\title{
Recognition of the potentials for regional climate changes on effective precipitation oscillations for vegetables in Ghazvin City
}

\author{
Ali Shakoor ${ }^{1^{\star}}$, Ali shamsoddini ${ }^{1}$, Mohaddeseh Hatami ${ }^{2}$ \\ ${ }^{1}$ Department of Geography, Marvdasht Branch, Islamic Azad University.,Marvdasht Iran. \\ ${ }^{2}$ Department of Geography, Mashhd Branch Islamic Azad University, Mashhad Iran
}

Accepted 26 July, 2011

\begin{abstract}
The present research focuses on both past and future time scale in order to recognize the changes of effective precipitation trend in Ghazvin station. Therefore, in order to recognize the trend and behavior of past climate components, the components trend analysis have been done using Pierson and linear regression method. In order to study and analyze effective precipitation trend, the length of statistical data from 1959 to 2009 and data on climate temperature, precipitation, evapotranspiration, wind speed and radiation have been used. SCS method is used in calculating the effective precipitation. Also, the compound results of two models of CNRM-GISS-EH and CM3 have been used to evaluate the effect of regional climate change in the simulation of effective precipitation in 2050 and 2075 decades. The results of changes in effective precipitation trend for study period (1959 to 2009) indicates that the effective precipitation trend in spring is decreasing with the rate $r=-0.10$, however, the results in winter $(r=0.11)$, autumn $(r=0.24)$, and summer $(r=0.16)$ indicates the increase of effective precipitation in recent decades. Also, it should be stated that the maximum increase of effective precipitation occurs in December with the rate $6 \mathrm{~mm}$ and the maximum decrease is in January with -1.91 in each decade. But, the average of the simulated results by the year 2075 indicates that the maximum decrease of effective precipitation is in July with $35.1 \%$ and the maximum increase will occur in August with $\mathbf{8 0 . 6 \%}$. Finally, however, the results indicate that the annual effective precipitation value in 2025 is increased with $(1.7 \%)$ and in 2075 with (14.5\%), but the great oscillation of these changes at summer, which is a dry period in Ghazvin, needs further management and planning for supplying the water requirement of different farming products, especially dry cultivation.
\end{abstract}

Key words: Climate change, carbon dioxide increase, dry farming, effective precipitation, SCS, Ghazvin.

\section{INTRODUCTION}

Precipitation is the most vital element of climate which almost influences all dimensions in the earth. The effect of precipitation on different human activities including farming, industry and services is obvious directly, indirectly, or with intermediate. In this regard, the relation between precipitation and farming, especially dry farming, is considerable and is somehow distinct from other activities. With a little reflection, it becomes clear that probably the most natural kind of using precipitation at farming section is dry farming. Land irrigation is indeed an artificial supply for plant water requirements. This is accomplished in regions and times, when the plant's moisture requirement is not met and provided naturally. With regard to the role of precipitation in dry farming, time distribution as well as rainfall rate and intensity are so important. Poor precipitation distribution over the year and also oscillation in the annual rate of precipitation are mainly the main factors for inefficiency of dry farming in 
some years (Azizi, 1379). Surely, at every time of rainfall, only some parts of precipitation is used by the plant and the rest of it is not at the access of the plant in different ways such as, evaporation, runoff and crossing through the root area.

So the concept of effective precipitation is used for that part of precipitation which directly, meets plant water requirement. However, the concept of effective precipitation from the view of surface water hydrology and also underground water hydrology is different from its concept in agriculture. From the view point of agricultural specialists, effective precipitation is a part of the total precipitation which directly meets the plant's water requirement and also surface runoff which could be pumped from lakes and wills to farm for the purpose of crop production.

With regard to dry farming, when land is left fallow, parts of the whole rain, which stored in soil for the next production, is also considered as an effective rain (Malek, 1362). Hayes and Buell (1955) consider effective precipitation as that quantity which is available for plant growth and amounts to total precipitation minus run-off and evaporation.

In this definition aspects prior to sowing are neglected, therefore, Ogrosky and Mockus (1964) defined effective rainfall as the total rainfall during the growing season minus moisture lost as runoff or percolation. Israelsen and Hansen, (1962) referred to the interesting point that mild raining on leaf surface or ground, even if it does not reach the root, could decrease the plant evaporation (Azizi, 2000).

In general, it could be concluded that, if we subtract the amount of percolation to the depth lower than the plant's root access, the quantity of runoff and also the amount of moisture remained in soil after harvesting in growth period or growth season, from the total quantity of rain in the same growth season or period, the effective rain is obtained, which might be equal, more, or less than the plant water requirement. With regard to effective rain estimation, mainly, because of the relatively high costs of employing precise tools and methods, experimental methods have been used. In this regard, reports of Soil Conservation Service of U.S.A. Department of Agriculture (1950, 1970. 1972), and also

FAO reports (1987), and in IRAN Koochaki and Kamali (1996), Koochaki (1997), Malek (1983), Roshan and Grab (2012). could be cited as examples.

\section{MATERIALS AND METHODS}

Generally, the present article focuses mainly on two past and future time scales. Therefore, in order to recognize the trends and behaviors of past climate components, the components trend analysis have been done using Pierson and linear regression method. In order to study and analyze effective precipitation trend, the length of statistical data from 1959 to 2009 have been used, also components of climate temperature, precipitation, evapotranspiration, wind speed and radiation have been employed for calculating effective precipitation and evapotranspiration. However, in calculating the effective precipitation and evaporation, the following terms have been considered: (SCS, 1972, Dastin, 1983, Ali, 1997).

\section{Calculation of effective precipitation}

With regard to effective rain estimation, mainly, because of the relatively high costs of employing precise tools and methods, experimental methods have been used. In the present research, U.S.A. Soil Conservation Service (SCS) has been employed. The reason why this method has been chosen is that it does not require any especial tool and also it has not been provided for a certain species of plant or soil. In this method, the effective rain is calculated based on monthly rainfall and evapotranspiration and also the depth of water storage or depth of irrigation. The general form of the relation used in this method is as follows (Ghasem Aziz, 2000): Equation (1)

$$
p_{e}=F\left(1.253 P^{.824}-2.935\right) \times 10^{.001 E t p}
$$

Where $\mathrm{Pe}$ is monthly effective rain, $\mathrm{P}$ is total precipitation per year, Etp is total evapotranspiration per month, and $F$ is a coefficient which is dependant to the depth of irrigation (Di). The depth considered in this study is $0.75 \mathrm{~mm}$ which is considered as a normal depth in most studies.

\section{Calculation of evapotranspiration using penman method}

The equations used in combined methods or, Penman method are as follows in practice (equations 2 to 6 ):

$$
\begin{aligned}
& E T_{\circ}=\frac{\Delta R_{n}-\gamma E_{a}}{\Delta+\gamma} \\
& \Delta=\frac{4098 e_{s a}}{\left(T_{a}-237.3\right)^{2}} \\
& e_{s a}=\exp \left(\frac{19.08 T_{a}+429.4}{T_{a}+237.3}\right) \\
& \gamma=\frac{1615 P_{a}}{2.49(10)^{6}-2.13(10)^{3} T_{a}} \\
& P_{a}=1013-0.1152 h+5.44(10)^{-6} h^{2}
\end{aligned}
$$

In above equitation: $\mathrm{ET}_{2}$ = Evapotranspiration of grass reference plant, $=\Delta$ Slope of saturation vapor pressure curve in proportion to temperature at the point where temperature is equal to $\mathrm{Ta}, \mathrm{Ta}=$ Temperature based on which evapotranspiration is calculated $\mathrm{Rn}=$ Net radiation

$\mathrm{Y}=$ Psychrometric constant

$\mathrm{Ea}=$ Aerodynamic particle which depends on real and saturated vapor pressure and wind speed Esa = saturated vapor pressure per Ta temperature, $\mathrm{Ea}=$ Actual pressure of water vapor in the air $\mathrm{Pa}=$ Air pressure, $\mathrm{H}=$ height above sea level, Penman presented the following equitation for Ea: Equitation (6):

$$
E_{a}=(0.2625+0.1409 U)\left(e_{s a}-e_{a}\right)
$$

Where $U$ is the wing speed in meter per second. 


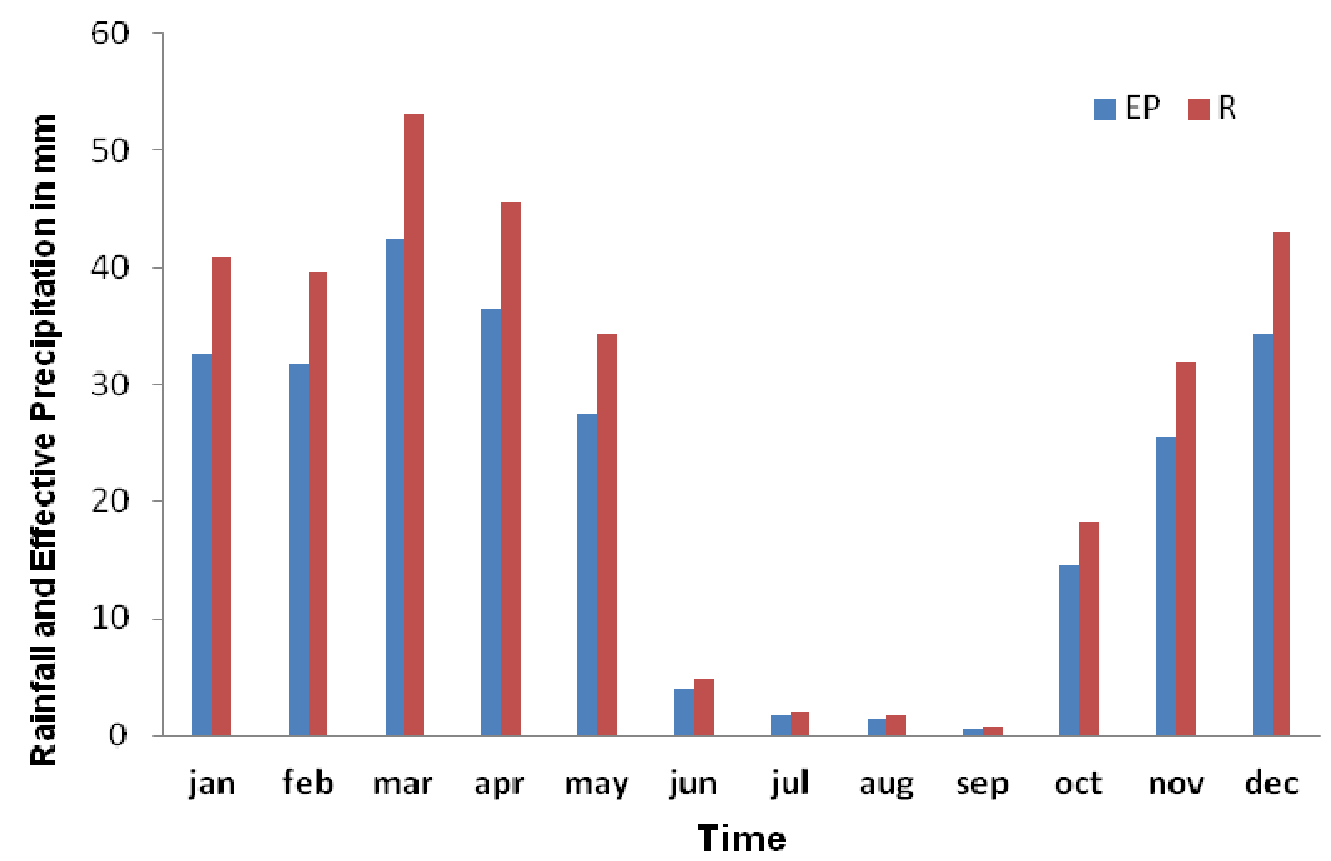

Figure 1. Values of monthly precipitation average and monthly effective precipitation average with regard to the statistical period from 1959 to 2009 for Ghazvin.

\section{GCM models}

Consequently, to simulate the effect of global warming and regional climate change CNRM-CM3 and GISS-EH models have been used. For this purpose, p50 scenario has been considered. But to simulate the effect of global warming, the effective precipitation variations for the study period from 2050 to 2075 have been considered.

\section{FINDINGS AND DISCUSSION}

\section{Effective precipitation variations in recent decades}

The results of the present research for monthly precipitation average indicate that the maximum monthly precipitation has occurred in March with $53.13 \mathrm{~mm}$. and its minimum has been in September with 0.82 millimeter, while the annual precipitation average is $316 \mathrm{~mm}$. Therefore, the maximum precipitation is $133.69 \mathrm{~mm}$ that is $42.31 \%$ of the total precipitation occurs in winter, 93 $\mathrm{mm}$. which is $29.4 \%$ of the total annual precipitation occurs in autumn. $84.75 \mathrm{~mm}$. which is $26.81 \%$ of the total annual precipitation occurs in spring and finally $1.45 \%$ of the total annual precipitation with the amount of $4.59 \mathrm{~mm}$ occurs in summer. As the result, rainy seasons of Ghazvin station are in the cold period, and the warm period is associated with precipitation deficiency (Figure 1). In the analysis done for the variation of effective precipitation trend in different months of the year, the results indicate that the maximum coefficient of effective precipitation changes is $241 \%$ which is in the month of
September, while the minimum effective precipitation changes coefficient has occurred in March that is 58.5\%.

The results indicate variation coefficient of $27.7 \%$ for annual effective precipitation variations. Therefore, as we proceed from cold to warm seasons and months of the year, the variation coefficient values are increased. So that the effective precipitation values are $62.43 \%$ in winter, $97.26 \%$ in autumn, $96,38 \%$ in spring and finally $191.29 \%$ in summer. However, despite the points stated above, we should not forget that the variation coefficient in spring with 0.88 is lower than that which is seen in autumn (Figure 2). In the analysis of monthly effective precipitation in different months of winter, it has been specified that except for January with $r=-0.10$ which shows the decrease of effective precipitation, two months of February with $(r=0.11)$ and March which $(r=0.18)$ shows the increase of effective precipitation. But in general, the results regarding the variation of effective precipitation trend in winter indicate its increase with the rate of $r=0.11$. In the analysis done for variation of effective precipitation trend in spring, except for January with $\mathrm{r}=-0.15$, in two other months of April and May, no special significant variation is seen (Figure 3 ).

However, in general these variations for spring with $r=-$ 0.10 indicate the effective precipitation decrease in this period, while with the weak trend. With regard to the results of $r^{2}$ and $r$ for the months of summer, just the month of July with $r=0.16$ indicates the increase of this climate component in summer, and other months do not show any significant trend. Also, the total variations even this climate component with $r=0.24$ is precipitation in 


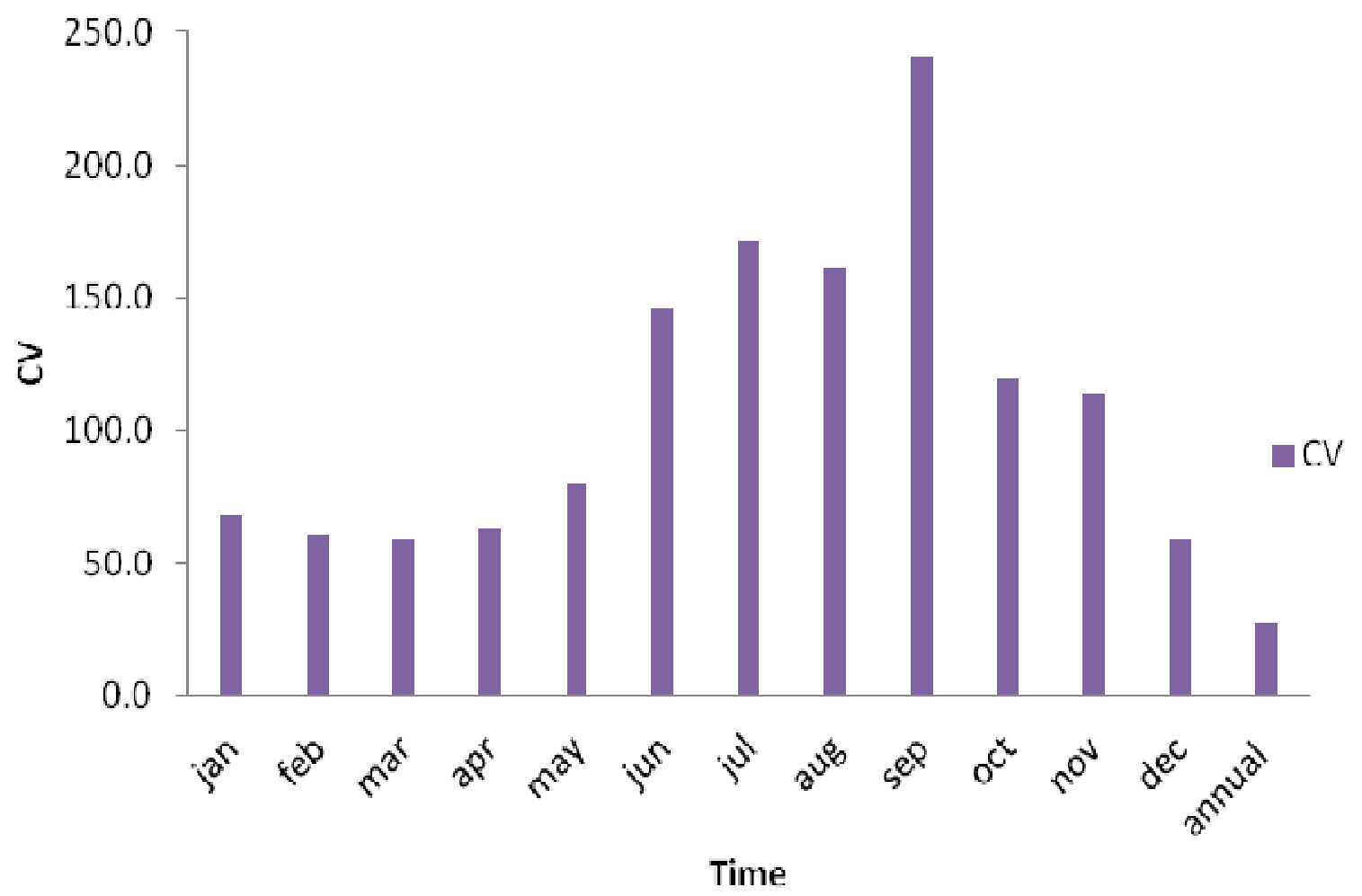

Figure 2. Percent values of monthly and annual effective precipitation variation coefficient for Ghzvin station.

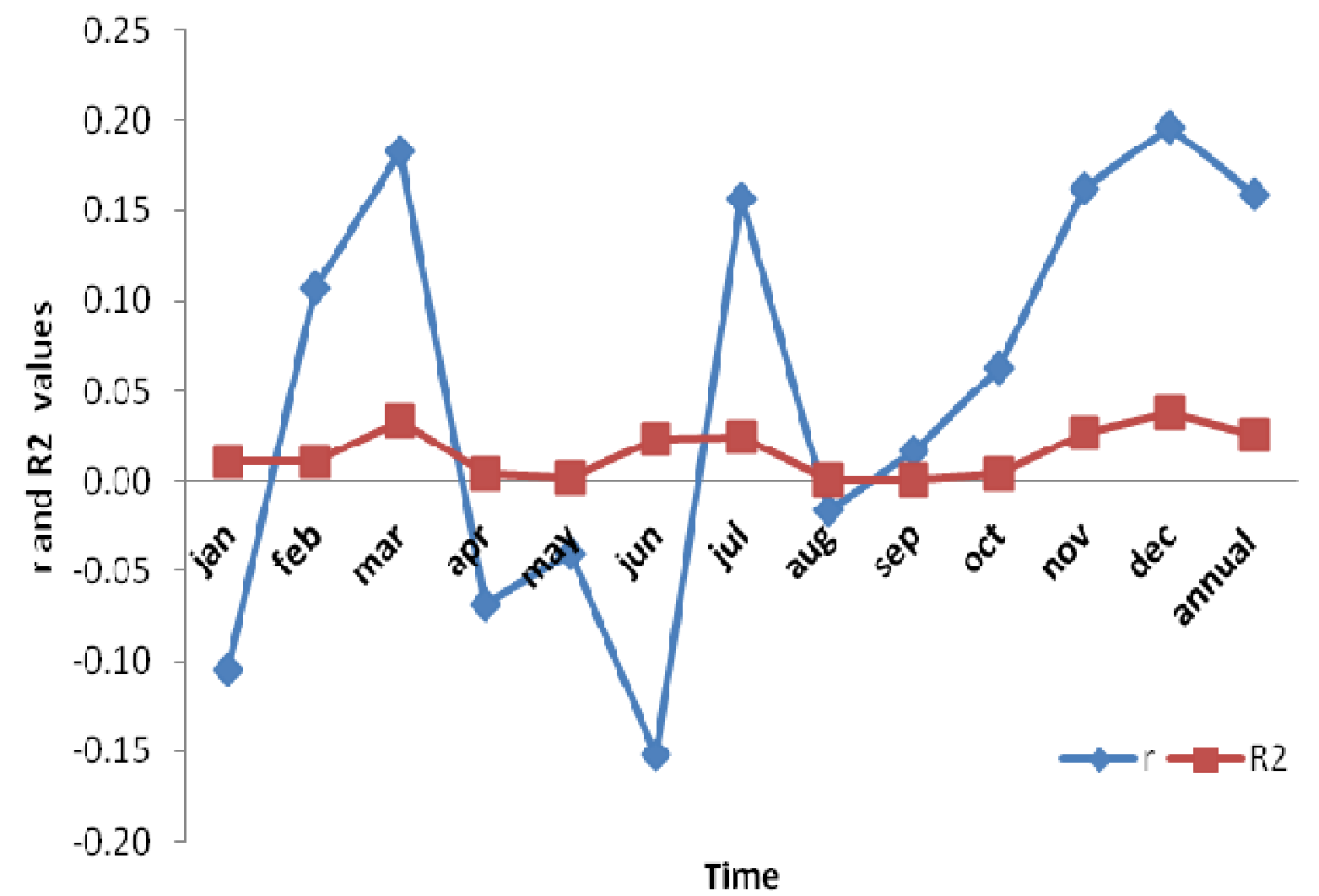

Figure 3. $r$ and $R^{2}$ Values for the variations of annual and monthly effective precipitation trend in Ghazvin station. 


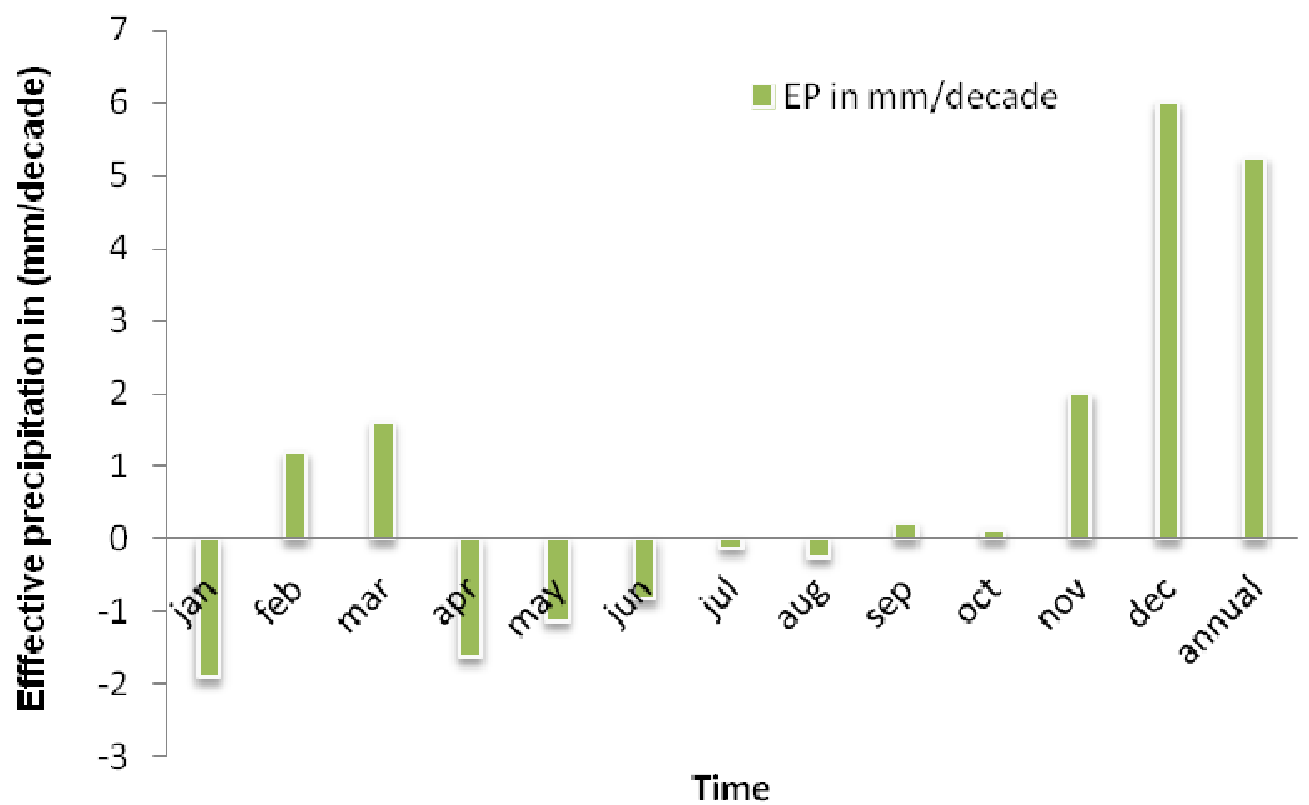

Figure 4. A decadal variation of effective precipitation from 1959 to 2009 for Ghazvin station.

recent decades with $r=0.11$. Finally, autumn as a first cold period of the year in Ghazvin shows the increase of effective precipitation in recent decades with $r=0.16$ in November and $r=0.20$ in while the $r$ value in October is not significant. Therefore, in general, the trend of variations in autumn indicates that randomly indicate increasing trend of effective December, significantly increasing (Figure 3). Finally, the results of variations in annual effective precipitation trend indicate the increase of this climate variable with $r=0.16$ in Ghazvin station.

In the analysis done for decadal variations of effective precipitation in Ghazvin station, the results show that the highest increasing variations of effective precipitation from 1959 to 2009 is $6 \mathrm{~mm}$ in each decade, and January with $0.91 \mathrm{~mm}$. decrease in effective precipitation in each decade shows the maximum drop or decrease in the past decades. However these variations for annual effective precipitation show increase with the rate of $5.24 \mathrm{~mm}$. per decade. What is clear about a decadal variation in each season is that the most effective precipitation decrease for reach decade occurred in spring with $-3.6 \mathrm{~mm}$ and highest increase is $8.12 \mathrm{~mm}$ in autumn. However, winter with $0.89 \mathrm{~mm}$. Increase and summer with $-0.19 \mathrm{~mm}$ decrease are in the next ranks (Figure 4).

\section{Simulation of effective precipitation in $\mathbf{2 0 5 0}$ and 2075 decades}

In this part of the research, in order to simulate the effect of regional climate variation on the oscillation of effective precipitation in Ghazvin station, we have applied the combinational results from the two models of CNRM-CM3 and GISS-EH. Moreover, the scenario p50 has been used in this research. As we can see in Figure 5, these precipitation variations oscillation for 2050 shows the maximum decrease of precipitation with $-96.2 \%$ in March and the maximum increase of effective precipitation with $79.6 \%$ is in August as compared with long term mean of 1961 to 1990 . But the average annual precipitation variation in 2050 shows the value of $2.1 \mathrm{~mm}$ in this year. While, the monthly precipitation variations in 2075 indicate an oscillation from $-51.3 \%$ in July to $121.8 \%$ in August. The mean of these variations for annual values indicate that annual precipitation value will be increased by about $18.3 \mathrm{~mm}$ in 2075 as compared with the long term average 1990 to 1961 .

The effective precipitation variation is similar to the monthly precipitation variation, with remark that, its portion has been decreased as compared with monthly precipitation. But, certainly there is no change in ranking different months with regard to their increase or decrease of effective precipitation as compared with monthly precipitation values. However, what is extracted from average monthly effective precipitation till the year 2075 indicates that the minimum decrease of effective precipitation with $-35.4 \%$ is in July and the maximum increase with the rate of $80 \%$ is in August as compared with the long term average from 1961 to1990 (Figure 6).

\section{Conclusion}

The results of the present research indicate that the concentration of precipitation in Ghazvin station is in the cold period of the year (autumn and winter). The total of 


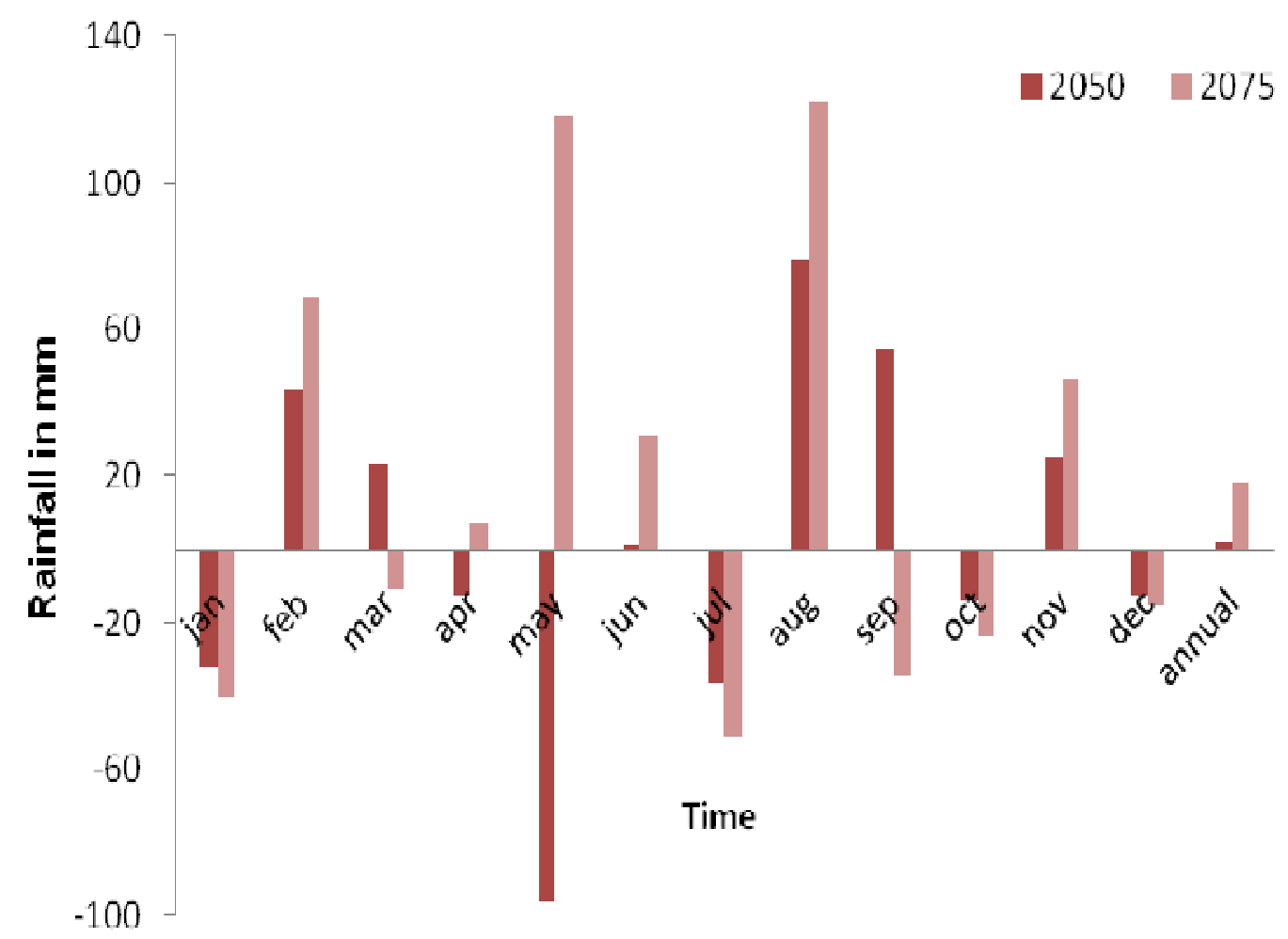

Figure 5. Annual and monthly precipitation variation in 2050 and 2075 decades for Ghazvin station.

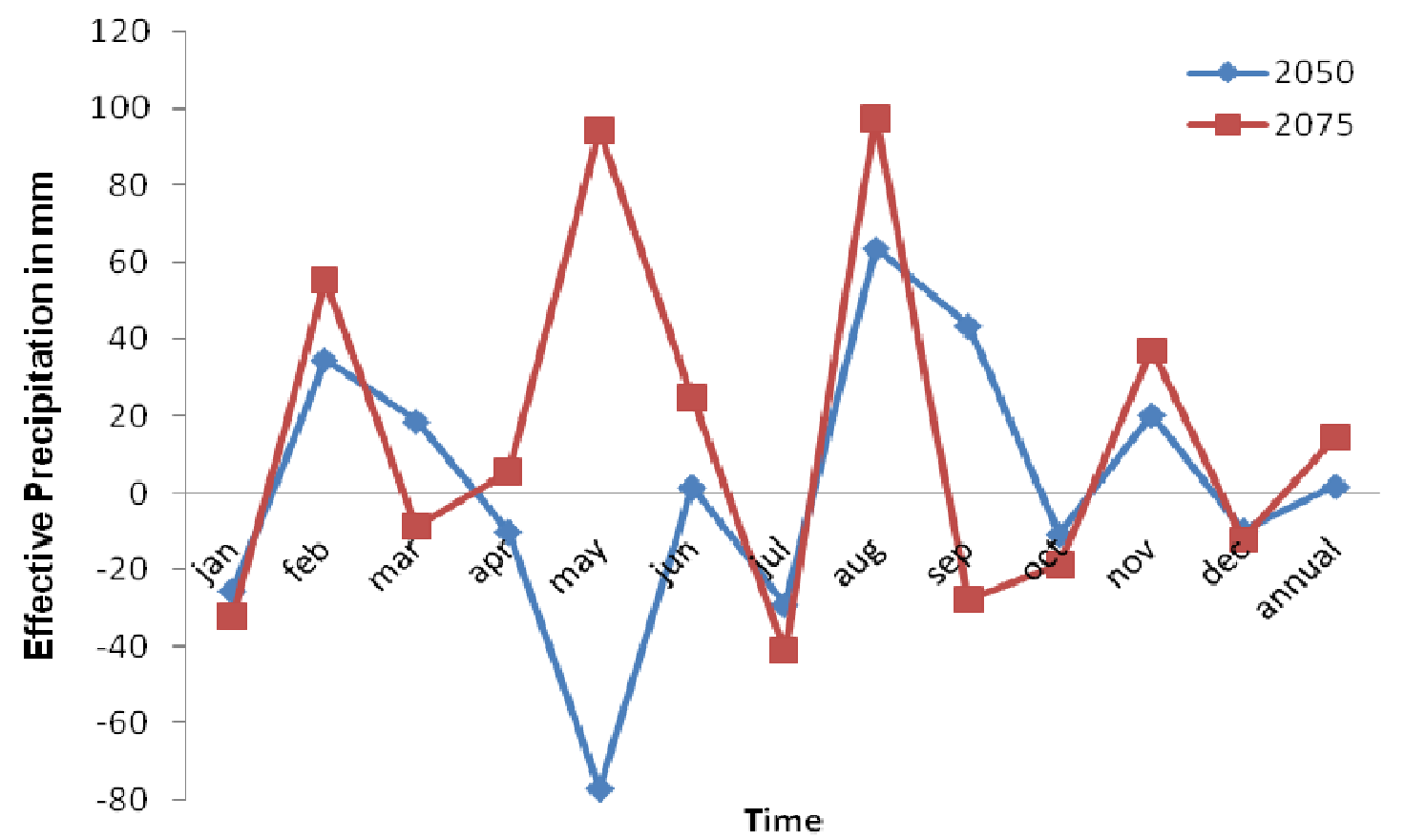

Figure 6. Annual and monthly effective precipitation variation in 2050 and 2075 decades in Ghazvin station.

this precipitation in winter and autumn is $72.9 \%$ of the total annual precipitation in Ghazvin. However, it should be mentioned that the minimum monthly precipitation in
Ghazvin with $0.82 \mathrm{~mm}(\mathrm{CV}=141 \%)$ is in September and the maximum with $53.13 \mathrm{~mm}(\mathrm{CV}=58 \%)$ is in March. In the analysis for effective precipitation component varia- 
tions (2009 to 1959), the results have shown that spring season with $r=-0.10$ has decreasing trend, while, in winter $(r=0.11)$, autumn $(r=0.24)$ and summer $(r=0.16)$ in the recent decades it shows an increasing trend. Also, it should be mentioned that the maximum decadal increase of the effective precipitation has occurred in December with $6 \mathrm{~mm}$ and the minimum decrease is in January with 1.91 per decade.

Another interesting point is that, decadal variations for annual effective precipitation indicate the increase in each decade with $5.24 \mathrm{~mm}$. Finally, after simulating effective precipitation values in 2050 and 2075 decades with the help of compound results of the two models of CNRM-CM3 and GISS- EH, we come to the conclusion that the maximum decrease of effective precipitation is in July with $-35.1 \%$ and the maximum increase with $80.6 \%$ is in August until the year 2075. While, the effective precipitation variations are, respectively as follows, in 2050 with the average of $1.7 \%$ and in 2100 with average variations of $14.5 \%$ indicates the effective precipitation increase. But it should not be neglected that the range of precipitation variations oscillation in the warm period of the year, especially in summer, is in the highest rate, which lead us to take proper decisions and have more management in the warm seam of the year to supply water requirements especially for dry farming of the region.

\section{ACKNOWLEDGMENT}

Special thanks goes to the Research Deputy of Islamic Azad University of Shiraz, for their financial contribution provided for financing cost for conducting this research, also I acknowledge Dr. Azizi, from Tehran University and Dr. Roshan, from Geographical Group of Golestan University, who have made the completion and improvement of this research article with their great and invaluable advices.

\section{REFERENCES}

Azizi GH (2000). Estimation of Effective Precipitation in relation with Dry Wheat Farming (case study: Khorramabad plain). Geogr. Res., 9(11): 115-123.

Koochaki E (1997). Effective Precipitation in Mashhad. Geogr. Res. Period., 10(3): 54-66.

Koochaki E, Nasiri MM (1996). Crops Ecology, first volume, ACECE of Mashhad. P. 329.

Koocheki A (1997). Water and Soil Relation in Crops, ACECE of Mashhad.P. 322.

Ali AF (1997). Estimation of major crop water requirements, agricultural education publication. P. 118.

Dastin NJ (1983). Effective Precipitation in Water Farming, translated by Esmaeil Malek, University Publication Center. P. 216.

Hayes GI, Buell JH (1955). water and our forests: Trees also need water at the right time and place in Hater yearbook, USDA.

Israelsen O, Hansen UE (1962). Irrigation Principle and practices, John Wiley and Sons, New York.

Ogrosky HO, Mackus V (1964). Hydrology of agricultural lands. Sec. 21 in Handbook of hydrology by V. T. Chow. New York. McGraw Hill, Book Co. Pp. 1-79.

SCS (1972). U.S. Soil conservation service, National Engineering handbook, hydrology. Section 4.

USDA (1970). Soil Conservation Irrigation water requirement.

WWW.Fao.Org. 